\title{
Efeitos da umidade relativa do ar na incubação e da idade da matriz leve sobre a eclodibilidade, qualidade dos pintos recém-eclodidos e desempenho da progênie
}

\author{
[Effects of relative air humidity in the incubator and breeder hen age on \\ hatchability, hatchling quality and progeny performance] \\ V.M. Barbosa ${ }^{1}$, N.C. Baião ${ }^{2}$, L.J.C. Lara ${ }^{2}$, J.S.R. Rocha ${ }^{3}$, M.A. Pompeu ${ }^{3}$, N.R.S. Martins ${ }^{2}$, \\ R.C. Leite $^{2}$, S.V. Cançado ${ }^{2}$,

\footnotetext{
${ }^{1}$ Pós-doutoranda do Instituto Nacional de Ciência e Tecnologia - Informação Genético-Sanitária da Pecuária Brasileira - Pecuária/Escola de Veterinária - UFMG - Bolsista CNPq

${ }^{2}$ Escola de Veterinária - UFMG - Belo Horizonte, MG

${ }^{3}$ Aluno de pós-graduação - Escola de Veterinária - UFMG - Belo Horizonte, MG
}

\section{RESUMO}

Objetivou-se avaliar os efeitos da umidade relativa do ar nas incubadoras (URI) e da idade da matriz leve sobre a eclodibilidade, qualidade dos pintos recém-eclodidos e o desempenho da progênie. Foram incubados 10.840 ovos, sendo os tratamentos definidos pela idade das matrizes Lohmann LSL ${ }^{\circledR}(26,41 \mathrm{e}$ 56 semanas) e pelos níveis de URI (48, 56 e 64\%). Após a incubação, 1.620 pintos fêmeas foram alojados em galpão experimental convencional, de acordo com os tratamentos, até as 12 semanas de idade. Para a avaliação de eclodibilidade sobre ovos férteis e fêmeas refugos, o delineamento experimental foi em blocos ao acaso no arranjo em parcelas subdivididas. A parcela foi a URI (três níveis) e a subparcela foi a idade da matriz (três idades). Os blocos foram constituídos pelos andares dos carrinhos de incubação, em que cada andar continha uma repetição de cada idade da matriz. Os nove tratamentos foram constituídos por 14 repetições cada. As repetições foram bandejas de incubação, constituindo 1.204 ovos por tratamento. Para a avaliação do desempenho das frangas, o delineamento experimental foi inteiramente ao acaso, constituído por um esquema fatorial 3x3 (três níveis de URI e três idades), com seis repetições de 30 aves em cada tratamento. A eclodibilidade sobre ovos férteis foi maior $(\mathrm{P} \leq 0,05)$ com a utilização de $56 \%$ de umidade relativa do ar durante a incubação, independentemente da idade da matriz; e ovos de matrizes mais velhas (56 semanas) apresentaram eclodibilidade menor $(\mathrm{P} \leq 0,05)$, independentemente do nível de umidade relativa do ar no interior das incubadoras. Não foram constatados efeitos da idade da matriz e URI sobre o percentual de pintos refugos. A URI ou a idade da matriz leve não afetam o desempenho da progênie.

Palavras-chave: incubação, umidade relativa do ar, matrizes leves, idade da ave, desempenho

\begin{abstract}
The aim of this study was to evaluate the effects of relative humidity in incubators (RHI) and breeder hen age on hatchability, hatchling quality and performance of progeny. 10,840 eggs were incubated, and the treatments were defined by the Lohmann $\operatorname{LSL}^{\circledR}$ breeder age $(26,41$ and 56 weeks) and the levels of RHI (48, 56 and 64\%). After incubation, 1,620 female chicks were raised in a conventional experimental shed, according to the treatments, until 12 weeks of age. To assess the hatchability of fertile eggs and unviable female chicks, the experimental design was randomized blocks in split plots design. The plot factor was the RHI and the subplot was the age of the breeder hens. The blocks were made by the floors of the incubation carriages, where each floor contained a repetition of each breeder age. The nine treatments consisted of 14 repetitions each. The repetitions were trays of incubation, with 1,204 eggs per treatment. To evaluate the performance of the progeny, the experimental design was completely randomized,
\end{abstract}

Recebido em 30 de setembro de 2013

Aceito em 24 de fevereiro de 2015

E-mail: vmichalsky@gmail.com 
consisting of a $3 \times 3$ factorial scheme with six replicates of 30 birds in each treatment. Hatchability of fertile eggs was higher $(P \leq 0.05)$ with the use of $56 \%$ relative humidity during incubation, regardless of breeder age, and the eggs from the oldest breeder hens (56 weeks) had lower hatchability $(P \leq 0.05)$, regardless of the level of relative humidity inside the incubator. No effects of breeder age and RHI on the percentage of unviable chicks were observed. The RHI or the age of the breeder hen does not affect the performance of progeny.

Keywords: age, breeder hen, incubation, performance, relative air humidity

\section{INTRODUÇÃO}

A umidade relativa do ar dentro das incubadoras (URI) é um dos principais fatores responsáveis pelo sucesso no processo de produção de pintos de um dia. Durante a incubação, a difusão de oxigênio para dentro do ovo e a eliminação de água e dióxido de carbono para o ambiente são proporcionais e simultâneas. Essa perda de água do embrião para o meio externo possibilita o surgimento da câmara de ar (Taylor, 1999). No momento em que o pinto perfura a câmara de ar, necessita encontrá-la de tamanho adequado para efetuar com êxito a transição da respiração corioalantóidea para a pulmonar e completar com sucesso a eclosão (Salazar, 2000; Molenaar et al., 2010; Noiva et al., 2014). Consequentemente, as diferenças nas pressões de gases e vapores de água afetam o intercâmbio entre o interior do ovo e seu ambiente e a fisiologia do embrião (Barbosa et al., 2013).

Devido às diferentes características da casca dos ovos de matrizes novas e velhas, principalmente no que se refere à condutância, French e Tullett (1991) sugeriram que é possível ajustar a URI baseando-se na idade da matriz. De acordo com Vick et al. (1993), os melhores índices de URI para a incubação de ovos de matrizes pesadas, jovens e velhas, são de 50 e $58 \%$, respectivamente. Isso porque a estrutura da casca dos ovos de matrizes jovens oferece maior resistência à difusão de gases e vapor de água do que aqueles produzidos pelas aves velhas. A baixa URI na incubação de ovos de galinhas velhas provoca excessiva perda de água dos ovos, resultando em baixa eclodibilidade.

Para a incubação de ovos de matrizes da linhagem Hy-Lyne White Leghorn ${ }^{\circledR}$, Buhr (1995) observou que, para ovos de galinhas consideradas jovens (34 semanas de idade), a melhor taxa de URI foi de 55\%, enquanto os teores de UR de 40, 55 e $70 \%$ não tiveram influência sobre a taxa de eclosão dos ovos produzidos pelas matrizes mais velhas, com 49 semanas de idade. Em estudo de Bruzual et al. (2000), a eclosão de ovos férteis de matrizes pesadas, com idades de 26 e 31 semanas de idade, não teve efeito das URI (43, 53 e 63\%) do $16^{\circ}$ ao $21^{\circ}$ dia de incubação. Entretanto, o ganho de peso, a conversão alimentar e a taxa de mortalidade foram melhores para as aves originadas dos ovos incubados com 53\% de URI no final do período de incubação, independentemente da idade da matriz. Trabalhando com matrizes pesadas jovens, Peebles et al. (2001) sugeriram que há uma depressão na embriogênese com a redução da URI para $43 \%$. Segundo os autores, esse fato pode acentuar um desempenho insatisfatório após a eclosão e também resultar em problemas de qualidade e desempenho dos pintos, causados por alta ou baixa umidade na incubadora.

De acordo com Decuypere et al. (2003) e Meir e Ar (2008), se a URI for muito baixa, haverá perda excessiva de umidade dos embriões, prejudicando a eclosão e resultando em pintos pequenos e desidratados. Por outro lado, se a URI for muito alta, os embriões tendem a eclodir precocemente. Em casos extremos, os pintos podem eclodir sem alcançarem o pleno desenvolvimento. King'ori (2011) relatou que as consequências indesejáveis da utilização de níveis inadequados de URI durante o processo de incubação poderiam também estender-se ao período de criação das aves, visto que a qualidade dos pintos é comprometida.

Entre as análises comumente utilizadas para avaliar desempenho em aves, como peso, ganho de peso, consumo de ração, conversão alimentar e viabilidade, Leeson e Summers (1984) descreveram que a medida do comprimento do tarsometatarso das aves é um critério para avaliar o tamanho corporal, além de ter sido sugerida como uma medida representativa do tamanho do esqueleto, auxiliando na análise de desempenho da progênie de matrizes leves. Oliveira (1996) 
relatou que o desenvolvimento corporal das frangas de postura, abrangendo a formação da estrutura óssea e da musculatura, ocorre até 12 a 13 semanas de idade. Posteriormente, as aves desenvolvem os órgãos de reprodução e aumentam o peso de vísceras até 18 semanas de idade. Nessa fase aproximadamente inicia-se a postura, caracterizada por um período crítico em que se refletem as condições de recria. Em consequência, frangas bem alimentadas, com peso e desenvolvimento corporal adequados, obtêm desempenho satisfatório durante a fase de produção.

Van Der Pol et al. (2013) compararam faixas entre 30 a $35 \%$ e 55 a $60 \%$ de URI até o $18^{\circ}$ dia de incubação em matrizes pesadas e não observaram diferenças significativas na qualidade dos pintos recém-eclodidos e no desempenho pós-eclosão, quando a temperatura de $37,8^{\circ} \mathrm{C}$ foi mantida constante durante o processo. Os pesquisadores sugerem que os embriões podem se adaptar a diferentes umidades relativas do ar até que o início do processo de eclosão se inicie, se a temperatura é mantida constante.

A maioria dos estudos publicados relativos à URI se refere a ovos de matrizes pesadas. A escassez de pesquisas atuais sobre o efeito da idade da matriz leve e da URI na incubadora tem dificultado a definição de níveis adequados nas incubadoras para otimizar o segmento de postura. Dessa forma, objetivou-se avaliar os efeitos da umidade relativa do ar na incubação e da idade da matriz leve sobre a eclodibilidade de ovos férteis, qualidade dos pintos recémeclodidos e o desempenho da progênie.

\section{MATERIAL E MÉTODOS}

Foram utilizados ovos de matrizes leves da linhagem Lohmann LSL ${ }^{\circledR}$, produzidos no mesmo dia. No incubatório, esses ovos foram armazenados na sala de ovos durante quatro dias, em temperatura média de $19,5^{\circ} \mathrm{C}$ e $85,9 \%$ de umidade relativa, onde foi realizada a seleção dos ovos, eliminando aqueles não incubáveis (sujos, trincados, quebrados, pequenos, com duas gemas e deformados). Após a seleção, foi feita classificação de acordo com o peso, estabelecendo-se uma categoria de peso para cada idade de matriz. As categorias de peso foram de 54,5 a $57,0 \mathrm{~g}, 59,5$ a $61,0 \mathrm{~g}$ e de 59,5 a 61,5g para os ovos das matrizes com 26, 41 e 56 semanas de idade, respectivamente.

A definição dos tratamentos está apresentada na Tabela 1.

Tabela 1. Definição dos tratamentos de acordo com a URI e a idade das matrizes

\begin{tabular}{ccc}
\hline Tratamentos & $\begin{array}{c}\text { Umidade } \\
\text { Relativa do Ar } \\
\text { na Incubadora } \\
(\%)\end{array}$ & $\begin{array}{c}\text { Idade das } \\
\text { Matrizes } \\
\text { (semanas) }\end{array}$ \\
\hline B N & 48 & 26 \\
B M & 48 & 41 \\
B V & 48 & 56 \\
M N & 56 & 26 \\
M M & 56 & 41 \\
M V & 56 & 56 \\
A N & 64 & 26 \\
A M & 64 & 41 \\
A V & 64 & 56 \\
\hline
\end{tabular}

Foram utilizadas três incubadoras idênticas (modelo Casp ${ }^{\circledR}$ M57 RE), com capacidade para 19.264 ovos cada, localizadas na mesma sala de incubação. A temperatura do bulbo seco foi de $37,2^{\circ} \mathrm{C}$. Para controle da temperatura do termômetro de bulbo úmido, o termostato foi regulado para $27,8^{\circ} \mathrm{C}, 29,4^{\circ} \mathrm{C}$ e $31,1^{\circ} \mathrm{C}$, correspondendo aos teores de URI de $48 \%, 56 \%$ e $64 \%$, respectivamente. Antes da incubação, os ovos foram pré-aquecidos durante seis horas em temperatura média de $27,5^{\circ} \mathrm{C}$.

Em cada uma das máquinas de incubação, os ovos foram colocados em um carrinho com 14 andares, com capacidade de quatro bandejas por andar. A posição das bandejas em cada andar foi determinada por sorteio. Com 456 horas de incubação (19 dias), todos foram transferidos para bandejas de eclosão. As bandejas com os ovos foram colocadas em um único nascedouro (modelo Casp ${ }^{\circledR} 108 \mathrm{HR}$ ), com capacidade para 19.264 ovos. Nessa máquina, o termostato foi regulado para manter a temperatura em $37,2^{\circ} \mathrm{C} \mathrm{e}$ a umidade relativa do ar em $73 \%$. As bandejas de eclosão foram posicionadas de forma que em cada andar da máquina contivessem bandejas dos nove tratamentos, distribuídas por sorteio. Os demais espaços das máquinas foram preenchidos com ovos dos mesmos lotes de matrizes, os quais não fizeram parte desta pesquisa. 
A retirada dos pintos do nascedouro ocorreu com 512 horas ( 21 dias e 8 horas) de incubação. A taxa de eclosão de fêmeas em relação ao número de ovos férteis foi obtida dividindo-se o número de fêmeas nascidas pelo número de ovos férteis, expressa em percentual. As fêmeas recémeclodidas foram submetidas a uma seleção de acordo com critérios previamente estabelecidos por Boleli (2013), e aquelas que apresentavam defeitos físicos, tais como bico torto, cegueira, umbigo aberto, desidratação, plumagem pegajosa, pescoço e/ou pernas tortas, foram classificadas como refugos. $\mathrm{O}$ percentual de fêmeas "refugos" foi obtido dividindo-se o número de fêmeas "refugos" pelo número total de fêmeas nascidas.

Para as avaliações de desempenho, foi tomada ao acaso uma amostra de 180 pintos por tratamento, os quais foram alojados em um galpão experimental convencional, dividido em 54 boxes de $3 \mathrm{~m}^{2}$ cada. Os 180 pintos de cada tratamento foram divididos em seis boxes com 30 aves cada, totalizando 1.620 aves alojadas.

A água e a ração foram fornecidas à vontade. Todos os pintos foram debicados com nove dias de idade. O período experimental foi de um dia a 12 semanas de idade das aves. A ração utilizada foi a mesma para as aves de todos os tratamentos. A fórmula da ração e os níveis nutricionais utilizados foram os mesmos durante todo o período do experimento. Para a formulação da ração e cálculo dos níveis nutricionais (Tab. 2), foram considerados os valores nutricionais dos ingredientes estabelecidos nas tabelas brasileiras sobre exigências nutricionais de aves e suínos (Rostagno et al., 2000).

Todas as aves foram pesadas no dia do alojamento, na $4^{\mathrm{a}}, 8^{\mathrm{a}}$ e $12^{\mathrm{a}}$ semanas de idade. $\mathrm{O}$ ganho de peso foi calculado descontando-se o peso inicial dos pintos ao alojamento. Os dados de consumo de ração foram registrados semanalmente. Os dados de consumo de ração acumulado foram obtidos pela soma do consumo de ração em cada período. $O$ cálculo da conversão alimentar foi feito considerando o consumo de ração acumulado e ganho de peso acumulado das aves ao final da $4^{\mathrm{a}}, 8^{\mathrm{a}}$ e $12^{\mathrm{a}}$ semanas de idade das frangas. O número de aves mortas foi registrado diariamente e, a partir da taxa de mortalidade, foi calculada a percentagem de viabilidade em cada período. Quando as aves completaram 12 semanas de idade, foram apanhadas ao acaso seis aves por repetição, constituindo uma amostra de 36 aves por tratamento. Essas frangas foram pesadas individualmente e o comprimento do tarsometatarso foi medido com um paquímetro (precisão $=0,01 \mathrm{~cm}) . \mathrm{O}$ comprimento do tarsometatarso foi correspondente à distância entre a articulação tibiotársica e o coxim plantar da perna direita.

Tabela 2. Composição percentual da ração inicial e seus respectivos níveis nutricionais calculados

\begin{tabular}{ll}
\hline Ingredientes & $(\%)$ \\
\hline Milho Grão & 64,85 \\
Farelo de soja (45\%) & 28,18 \\
Farinha de carne e ossos (40\%) & 6,19 \\
Sal comum & 0,28 \\
L-lisina HCL & 0,05 \\
DL-metionina & 0,15 \\
Colina (70\%) & 0,05 \\
Bacitracina de Zinco (15\%) & 0,05 \\
Nicarbazina & 0,05 \\
Suplemento Vitamínico Mineral* & 0,15 \\
\hline TOTAL & 100 \\
\hline Níveis Nutricionais calculados & 2945 \\
\hline Energia (kcal/kg) & 21,00 \\
Proteína bruta (\%) & 1,00 \\
Cálcio (\%) & 0,71 \\
Fósforo total (\%) & 0,49 \\
Fósforo disponível (\%) & 0,19 \\
Sódio (\%) & 1,10 \\
Lisina total (\%) & 0,82 \\
Met + Cis total (\%) & 0,47 \\
Metionina total (\%) & 0,79 \\
Treonina total (\%) & 0,23 \\
Triptofano total (\%) & \\
\hline *Produto comercial: Suplemento Vitamínico Mineral. \\
Cada 1,0kg contém: Vit. A 3.500.000UI, Vit. D3 \\
625.000UI, Vit. E 6.250mg, Vit. K3 750mg, Vit. B1 \\
500mg, Vit. B2 1.250mg, Vit. B6 1.000mg, Vit. B12 \\
6.250mcg, Biotina 25mg, Niacina 8.750mg, Ácido \\
Fólico 250mg, Ácido Pantotênico 3.000mg, Selênio \\
45mg, Iodo 175mg, Ferro 12.525mg, Cobre 2.500mg, \\
Manganês 19.500, Zinco 13.750mg, PC 18.750mg, \\
Antioxidante 500mg. & \\
& \\
&
\end{tabular}

Para a avaliação de eclodibilidade, infertilidade e fêmeas refugos, o delineamento experimental foi em blocos ao acaso no arranjo em parcelas subdivididas. $\mathrm{O}$ fator da parcela foi a URI (três níveis) e a subparcela foi a idade da matriz (três idades). Os blocos foram constituídos pelos 
andares dos carrinhos de incubação, em que cada andar continha uma repetição de cada idade da matriz. Os nove tratamentos foram constituídos por 14 repetições cada. As repetições foram as bandejas de incubação com capacidade para 86 ovos cada, constituindo 1.204 ovos por tratamento. Para a avaliação do desempenho das frangas, o delineamento experimental foi inteiramente ao acaso, constituído por um esquema fatorial $3 \times 3$, sendo três níveis de URI (48, 56 e 64\%) e três idades $(26,41$ e 56 semanas), com seis repetições de 30 aves em cada tratamento. Para a avaliação do comprimento do tarsometatarso, o delineamento experimental foi também inteiramente ao acaso, porém cada uma das 36 aves por tratamento foi considerada como uma repetição. Os dados normais e homogêneos foram submetidos às análises de variância e as médias comparadas pelo teste SNK (Sampaio, 2002). As médias das respostas não normais e não homogêneas foram comparadas pelo teste Kruskal-Wallis, utilizando o programa SAEG versão 9.1 (Sistema..., 2005).

A metodologia utilizada neste experimento foi aprovada pelo Comitê de Ética em Experimentação Animal da Universidade Federal de Minas Gerais - CETEA, sob protocolo $\mathrm{n}^{\circ}$ $218 / 08$.

\section{RESULTADOS E DISCUSSÃO}

Não houve interação entre as parcelas e subparcelas para nenhuma resposta estudada. Observa-se na Tabela 3 que as melhores taxas de eclosão em relação aos ovos férteis ocorreram quando os ovos foram incubados com a URI de 56\% ( $\mathrm{P} \leq 0,05)$, independentemente da idade da matriz. Possivelmente, os extremos de URI ( $48 \%$ e 64\%) proporcionaram perda excessiva e escassa, respectivamente, do interior do ovo para o meio ambiente, prejudicando a formação da câmara de ar e desenvolvimento embrionário em ambos os casos. Os resultados observados neste experimento foram semelhantes aos de Buhr (1995). Rosa et al. (2002), avaliando os efeitos da UR do ar (51, 56 e 61\%) na incubação de ovos de matrizes pesadas de 34 a 63 semanas de idade, encontraram os melhores resultados de eclodibilidade com a utilização de $51 \%$ de URI. Por outro lado, a eclodibilidade em relação aos ovos férteis das matrizes com 64 semanas de idade foi inferior à dos ovos das matrizes com 26 e 41 semanas de idade $(\mathrm{P} \leq 0,05)$, independentemente da URI utilizada. Esse resultado era esperado e encontra-se amplamente divulgado na literatura, visto que à medida que a ave envelhece a tendência é o aumento de peso, a queda de fertilidade, postura e eclosão de ovos férteis para matrizes.

Tabela 3. Porcentagem de eclosão de fêmeas, em relação aos ovos férteis, de acordo com a URI e a idade das matrizes

\begin{tabular}{ccccc}
\hline Idade da matriz & \multicolumn{3}{c}{ Umidade relativa do ar (\%) } & \multirow{2}{*}{ Média } \\
\cline { 2 - 4 } (semanas) & 48 & 56 & 64 & $39,0 \mathrm{a}$ \\
\hline 26 & 37,9 & 44,0 & 35,0 & $41,0 \mathrm{a}$ \\
41 & 40,6 & 42,2 & 40,0 & $35,1 \mathrm{~b}$ \\
56 & 33,0 & 38,4 & 34,1 & \\
\hline
\end{tabular}

Médias seguidas de letras distintas, minúsculas na coluna e maiúsculas na linha, são diferentes pelo teste SNK $(\mathrm{P} \leq 0,05) . \mathrm{CV}=14,4 \%$.

O percentual de pintos fêmeas recém-eclodidos refugos encontra-se na Tabela 4. Não foram constatados efeitos da idade da matriz e URI sobre os defeitos físicos analisados $(\mathrm{P}>0,05)$, como bico torto, cegueira, umbigo aberto, pescoço e/ou pernas tortas, desidratação e plumagem pegajosa. Segundo Boleli (2013), essas são anormalidades comumente apresentadas por aves recém-eclodidas que estão relacionadas com problemas de incubação, incluindo desvios de umidade, indicando que as URI testadas não promoveram alterações significativas na qualidade dos pintos recém- eclodidos. Van der Pol et al. (2013) trabalharam com diferentes URI e com o controle independente da temperatura e não observaram diferenças significativas na qualidade dos pintos recém-eclodidos e no desempenho da progênie. Segundo os pesquisadores, é possível que os embriões possam se adaptar a diferentes umidades relativas do ar até que o início do processo de eclosão se inicie, caso a temperatura seja mantida constante, indicando uma interação entre temperatura e umidade não estudada anteriormente nos experimentos sobre URI e um alerta para futuras pesquisas. 
Tabela 4. Percentagem, de pintos fêmeas recém-eclodidos refugos, de acordo com a URI e a idade das matrizes

\begin{tabular}{ccccc} 
Idade da matriz & \multicolumn{3}{c}{ Umidade relativa do ar (\%) } & Média \\
\cline { 2 - 4 } (semanas) & 48 & 56 & 64 & 1,2 \\
\hline 26 & 1,0 & 1,1 & 1,4 & 1,9 \\
41 & 3,4 & 0,8 & 1,5 & 2,9 \\
56 & 4,0 & 2,8 & 2,5 & \\
Média & 2,8 & 1,3 & 1,8 & \\
\hline
\end{tabular}

Médias na coluna e na linha são semelhantes pelo teste Kruskal-Wallis $(\mathrm{P}>0,05)$.

Os pesos dos pintos no momento do alojamento estão apresentados na Tabela 5. Os pintos descendentes das matrizes com 41 semanas de idade foram estatisticamente mais pesados do que aqueles produzidos pelas aves com 56 semanas, e estes, por sua vez, foram mais pesados do que os oriundos das aves com 26 semanas, independentemente do nível de URI $(\mathrm{P} \leq 0,05)$. De acordo com Tullet e Burton (1982), a variação no peso dos pintos pode ser influenciada pelo peso do ovo, e neste experimento as faixas de peso de ovos antes da incubação das matrizes com 56 e 64 semanas foram praticamente as mesmas. Independentemente da idade da matriz, o efeito da URI sobre o peso dos pintos foi significativo $(\mathrm{P} \leq 0,05)$. Os pintos nascidos dos ovos incubados com 56\% de URI tiveram o menor peso. Porém, os pintos nascidos na incubadora com URI de $64 \%$ foram os mais pesados, e os originados dos ovos incubados com $48 \%$ de URI tiveram pesos intermediários aos valores obtidos em 56\% e $64 \%$ de URI.

Tabela 5. Peso dos pintos fêmeas (em gramas) de acordo com a URI e a idade das matrizes

\begin{tabular}{ccccc} 
Idade da matriz & \multicolumn{3}{c}{ Umidade relativa do ar (\%) } & \multirow{2}{*}{ Média } \\
\cline { 2 - 4 } (semanas) & 48 & 56 & 64 & $34,6 \mathrm{c}$ \\
\hline 26 & 34,6 & 34,5 & 34,7 & $37,0 \mathrm{a}$ \\
41 & 37,0 & 36,7 & 37,4 & $36,7 \mathrm{~b}$ \\
56 & 36,7 & 36,4 & 37,0 & \\
Média & $36,1 \mathrm{~B}$ & $35,8 \mathrm{C}$ & $36,4 \mathrm{~A}$ & \\
\hline
\end{tabular}

Médias seguidas de letras distintas, minúsculas na coluna e maiúsculas na linha, são diferentes pelo teste SNK $(\mathrm{p} \leq 0,05) . \mathrm{CV}=1,0 \%$.

Os dados referentes ao ganho de peso de um dia a 12 semanas de idade (Tab. 6) foram semelhantes aos obtidos na $4^{\mathrm{a}}$ e $8^{\mathrm{a}}$ semanas e demonstram que as aves descendentes das matrizes com idade de 41 semanas apresentaram maior ganho de peso $(\mathrm{p} \leq 0,05)$ quando comparadas àquelas originadas das matrizes com 26 e 56 semanas de idade, que foram semelhantes entre si $(p>0,05)$. As aves descendentes das matrizes com 26 semanas demonstraram um ganho compensatório, pois no momento do alojamento os pintos tinham o menor peso $(\mathrm{P} \leq 0,05)$. Esses resultados se assemelham aos encontrados na literatura com matrizes pesadas, os quais indicam maiores ganhos de peso em aves procedentes de matrizes mais velhas (Peebles et al., 1999; Menocal et al.,
2003). Independentemente da idade da matriz, a URI não teve influência significativa $(p>0,05)$ sobre de ganho de peso de um dia a 12 semanas de idade, concordando com os resultados observados por Bruzual et al. (2000).

Os resultados do consumo de ração de um dia à $12^{\mathrm{a}}$ semana de idade (Tab. 7) não revelaram diferenças significativas entre os tratamentos ( $p>0,05)$, assim como aqueles obtidos na $4^{\mathrm{a}}$ e $8^{\mathrm{a}}$ semanas; indicando que tanto a idade da matriz como a URI não exerceram influência sobre o consumo de ração das frangas até a $12^{\mathrm{a}}$ semana de idade. Resultados análogos foram encontrados por Menocal et al. (2003), que trabalharam com frangos de corte oriundos de matrizes com 45 e 57 semanas de idade. 
Tabela 6. Ganho de peso das aves (em gramas) de um dia a 12 semanas de idade, de acordo com a URI e a idade das matrizes

\begin{tabular}{ccccc}
\hline Idade da matriz & \multicolumn{3}{c}{ Umidade relativa do ar (\%) } & \multirow{2}{*}{ Média } \\
\cline { 2 - 4 } (semanas) & 48 & 56 & 64 & $921,6 \mathrm{~b}$ \\
\hline 26 & 908,3 & 924,8 & 931,8 & $953,2 \mathrm{a}$ \\
41 & 964,6 & 945,2 & 949,9 & $932,4 \mathrm{~b}$ \\
56 & 920,7 & 938,5 & 938,0 & \\
\hline Média & $931,2 \mathrm{~A}$ & $936,2 \mathrm{~A}$ & $939,9 \mathrm{~A}$ & \\
\hline
\end{tabular}

Médias seguidas de letras distintas, minúsculas na coluna e maiúsculas na linha, são diferentes pelo teste SNK $(\mathrm{P} \leq 0,05) . \mathrm{CV}=2,9 \%$.

Tabela 7. Consumo de ração (em gramas) de um dia a 12 semanas de idade, de acordo com a URI e a idade das matrizes

\begin{tabular}{ccccc}
\hline Idade da matriz & \multicolumn{3}{c}{ Umidade relativa do ar (\%) } & \multirow{2}{*}{ Média } \\
\cline { 2 - 4 } (semanas) & 48 & 56 & 64 & 3153,9 \\
\hline 26 & 3076,1 & 3157,3 & 3228,4 & 3228,2 \\
41 & 3258,2 & 3202,1 & 3224,4 & 3186,0 \\
56 & 3166,1 & 3176,7 & 3215,1 & \\
Média & 3166,8 & 3178,7 & 3222,6 & \\
\hline
\end{tabular}

Médias na coluna e na linha são semelhantes pelo teste SNK (p>0,05). CV = 3,5\%.

A conversão alimentar na $12^{\mathrm{a}}$ semana (Tab. 8) apresentou resultados semelhantes $(\mathrm{P}>0,05)$ à $4^{\mathrm{a}}$ e $8^{a}$ semanas de idade das frangas. Não foram observadas diferenças entre os tratamentos $(\mathrm{P}>0,05)$. Em frangos de corte, a literatura relata que os pintos descendentes de galinhas mais velhas apresentam melhores índices de conversão alimentar do que aqueles originados de aves mais novas (Peebles et al., 1999; Menocal et al., 2003). Em relação aos efeitos da URI, os resultados obtidos neste experimento diferem daqueles encontrados por Bruzual et al. (2000), os quais observaram efeitos da URI sobre conversão alimentar dos frangos de corte.

Tabela 8. Conversão alimentar $(\mathrm{kg} / \mathrm{kg})$ de um dia a 12 semanas de idade, de acordo com a URI e a idade das matrizes

\begin{tabular}{ccccc}
\hline $\begin{array}{c}\text { Idade da matriz } \\
\text { (semanas) }\end{array}$ & \multicolumn{3}{c}{ Umidade relativa do ar (\%) } & \multirow{2}{*}{ Média } \\
\hline 26 & 3,39 & 56 & 64 & 3,42 \\
41 & 3,38 & 3,42 & 3,46 & 3,39 \\
56 & 3,44 & 3,39 & 3,39 & 3,42 \\
Média & 3,40 & 3,38 & 3,43 & \\
\hline
\end{tabular}

Médias na coluna e na linha são semelhantes pelo teste $\mathrm{SNK}(\mathrm{p}>0,05) . \mathrm{CV}=2,3 \%$.

A idade da matriz e a URI não tiveram efeitos $(\mathrm{p}>0,05)$ sobre a viabilidade das frangas até a $12^{\mathrm{a}}$ semana de idade (Tab. 9). Em se tratando de frangos de corte, há dados contraditórios na literatura. Segundo Menocal et al. (2003), a idade das reprodutoras não afeta a mortalidade de seus descendentes, mas, de acordo com Weitjens et al. (1999), a viabilidade dos pintos é menor quando estes são procedentes de matrizes jovens.
O comprimento do tarsometatarso é uma medida representativa do tamanho do esqueleto (Leeson e Summers, 1984), e o crescimento da estrutura óssea ocorre até 12 semanas de idade (Oliveira, 1996). Portanto, os resultados desta análise (Tab. 10) demonstram que o crescimento do esqueleto das aves não foi afetado $(\mathrm{P}>0,05)$ pela idade das progenitoras nem pela URI. 
Tabela 9. Viabilidade das frangas (\%) de um dia a 12 semanas de idade de acordo com a URI e a idade das matrizes

\begin{tabular}{ccccc}
\hline Idade da matriz & \multicolumn{3}{c}{ Umidade relativa do ar $(\%)$} & Média \\
\cline { 2 - 4 } (semanas) & 48 & 56 & 64 & 99,9 \\
\hline 26 & 100,0 & 99,9 & 100,0 & 99,9 \\
41 & 99,9 & 99,9 & 100,0 & 100,0 \\
56 & 100,0 & 100,0 & 100,0 & \\
Média & 99,9 & 99,9 & 100,0 &
\end{tabular}

Médias na coluna e na linha são semelhantes pelo teste SNK (p>0,05). CV = 0,2\%.

Tabela 10. Comprimento (centímetros) do tarsometatarso das frangas com 12 semanas de idade, de acordo com a URI e a idade das matrizes

\begin{tabular}{ccccc}
\hline \multirow{2}{*}{$\begin{array}{c}\text { Idade da matriz } \\
\text { (semanas) }\end{array}$} & \multicolumn{3}{c}{ Umidade relativa do ar (\%) } & Média \\
\cline { 2 - 4 } & 48 & 56 & 64 & 9,4 \\
41 & 9,4 & 9,3 & 9,4 & 9,4 \\
56 & 9,4 & 9,5 & 9,4 & 9,4 \\
Média & 9,4 & 9,5 & 9,5 & \\
\hline
\end{tabular}

Médias na coluna e na linha são semelhantes pelo teste SNK (P>0,05). CV = 3,0\%.

\section{CONCLUSÕES}

A eclodibilidade sobre ovos férteis provenientes de matrizes leves é otimizada utilizando-se o nível de $56 \%$ de URI, e os ovos de matrizes mais velhas têm a eclodibilidade reduzida, independentemente da URI. A URI de 48, de 56 ou de $64 \%$ não interferem na qualidade dos pintos recém-eclodidos e no desempenho das frangas até 12 semanas de idade.

\section{REFERÊNCIAS}

BARBOSA, V.M.; ROCHA, J.S.R.; POMPEU, M.A. et al. The effects of relative humidity and turning in incubators machines on the incubation yield and chick performance. World Poult. Sci. J., v.69, p.89-97, 2013.

BOLELI, I.C. Estresse, mortalidade e malformações. In: MACARI, M.; GONZALES, E. Manejo da incubação. 3.ed. Jaboticabal: FACTA, 2013. p.177-202.

BRUZUAL, J.J.; PEAK, S.D.; BRAKE, J. et al. Effects of relative humidity during the last five days of incubation and brooding temperature on performance of broiler chicks from young broiler breeders. Poult. Sci., v.79, p.1385-1391, 2000.

BUHR, R.J. Incubation relative humidity effects on allantoic fluid volume and hatchability. Poult. Sci., v.74, p.874-884, 1995.
DECUYPERE, E.; MALHEIROS, R.D.; MORAES, V.M.B. et al. Fisiologia do embrião. In: MACARI, M.; GONZALES, E. Manejo da incubação. 2.ed. Campinas: FACTA, 2003. p.6594.

FRENCH, N.A.; TULLETT, S.G. Variation in the eggs of various poultry species. In: TULLETT, S.G. (Ed.). Avian incubation. London: Butterworth-Heinemann, 1991. p.59-77.

KING'ORI, A.M. Review of the factors that influence egg fertility and hatchabilty in poultry. Int. J. Poult. Sci., v.10, p.483-492, 2011.

LEESON, S.; SUMMERS, J.D. Influence of nutritional modification on skeletal size of leghorn and broiler breeder pullets. Poult. Sci., v.63, p.1222-1228, 1984.

MENOCAL, J.A.; COELLO, C.L; GONZÁLEZ, E.A. Effects of the genetic strain and age of breeder hens on the productive performance of broilers. Vet. Mex., v.34, p.97-102, 2003.

MEIR, M.; AR, A. Changes in eggshell conductance, water loss and hatchability of layer hens with flock age and moulting. Br. Poult. Sci., v.49, p.677-684, 2008.

MOLENAAR, R.; REIJRINK, I.A.M.; MEIJERHOF, $\mathrm{R}$. et al. Meeting embryonic requirements of broilers throughout incubation: a review. Braz. J. Poult. Sci., v.12, p.137-148, 2010. 
NOIVA, R.M.; MENEZES, A.C.; PELETEIRO, M.C. Influence of temperature and humidity manipulation on chicken embryonic development. BMC Vet. Res., v.10, p.1-10, 2014.

OLIVEIRA, B.L. Aspectos atuais e futuros da nutrição de poedeiras. Cad. Tec. Vet. Zootec., n.17, p.5-10, 1996.

PEEBLES, E.D.; BURNHAM, M.R.; GARDNER, C.W. et al. Effects of incubational humidity and hen age on embryo composition in broiler hatching eggs from young breeders. Poult. Sci., v.80, p.1299-1304, 2001.

PEEBLES, E.D.; DOYLE, S.M.; PANSKY, T. et al. Effects of breeder age and dietary fat on subsequent broiler performance. 1. Growth, mortality and feed conversion. Poult. Sci., v.78, p.505- 511, 1999.

ROSA, P.S.; GUIDONI, A.L.; LIMA, I.L. et al. Influência da temperatura de incubação em ovos de matrizes de corte com diferentes idades e classificados por peso sobre os resultados de incubação. Rev. Bras. Zootec., v.31, p.10111016, 2002.

ROSTAGNO, H.S.; ALBINO, L.F.T.; DONZELE, J.L. et al. Tabelas brasileiras para aves $e$ suínos: composição de alimentos e exigências nutricionais. Viçosa: UFV, 2000.
SALAZAR, A.I. El proceso de incubación. Avic. Profes, v.18, p.26-30, 2000.

SAMPAIO, I.B.M. Estatística aplicada à experimentação animal. 2.ed. Belo Horizonte: FEPMVZ, 2002. 265p.

SISTEMA de análises estatísticas e genéticas. Versão 9.1. Viçosa: UFV, 2005.

TAYLOR, G. Understanding high yield broiler incubation. Zootec. Int., v.22, p.32-36, 1999.

TULLETT, S.G.; BURTON, F.G. Factors affecting the weight and water status of the chick at hatch. Br. Poult. Sci., v.23, p.361-369, 1982.

VAN DER POL, C.W.; VAN ROOVERTREIJRINK, I.A.M.; MAATJENS, C.M. et al. Effect of relative humidity during incubation at a set eggshell temperature and brooding temperature posthatch on embryonic mortality and chick quality. Poult. Sci., v.92, p.2145-2155, 2013.

VICK, S.V.; BRAKE, J.; WALSH, T.J. Relationship of incubator humidity and flock age to hatchability of broiler hatching eggs. Poult. Sci., v.72, p.251-258, 1993.

WEYTJENS, S.; MEIJERHOF, R.; BUYSE, J. et al. Thermoregulation in chicks originating from breeder flocks of two different ages. J. Appl. Poult. Res., v.8, p.139-145, 1999. 